\title{
Risk Assessement Represented by Pathogenic Microorganisms Regarding the Incidence of Foodboorne Ilnesses in a Representative County During 2013
}

\author{
Sorin D. DAN ${ }^{* 1}$, Marian MIHAIU ${ }^{1}$, Liora MIHAIU ${ }^{2}$, Darius CORDEA ${ }^{1}$, Ionuţ CORDIŞ ${ }^{1}$, Oana REGET, \\ Alexandra TĂBĂRAN ${ }^{1}$ \\ ${ }^{1}$ Department of Animal Production and Food Safety, Univesity of Agricultural Sciences and Veterinary \\ Medicine, Faculty of Veterinary Medicine, 3-5 Mănăștur Street, 400372, Cluj Napoca, Romania \\ ${ }^{2}$ Department of Pharmacology, University of Medicine and Pharmacy Iuliu Hatieganu, 8 Babeș Street, \\ 400012, Cluj Napoca \\ *Corresponding author, e-mail: sorindan@usamvcluj.ro
}

Bulletin UASVM Veterinary Medicine 71(2) / 2014,

Print ISSN 1843-5270; Electronic ISSN 1843-5378

DOI:10.15835/buasvmcn-vm: 10644

\begin{abstract}
:
The interest of the competent authorities regarding foodborne illnesses is increasing these days, although recently the combined effort of the food industry was managed through the monitoring system conducted by the state and the decreasing of the prevalence of pathogens in foods of animal origin, and thus the incidence of food poisoning. Despite the progress acquired in analytical techniques, undiagnosed cases often remain, thus not knowing the true incidence of these diseases. The aim of this paper was to assess the microbiological risk represented by the pathogenic germs in different foods of animal origin, associated with the incidence of foodborne illnesses in a representative County during 2013. The research material was represented by 10.947 samples of animal origin products: fresh meat, fresh poultry meat, poultry carcasses, minced meat, meat products, pasteurized liquid milk products, cheese manufactured from pasteurized and unpasteurized milk, butter, icecream, eggs, ready to eat foods and seafood, collected according to national surveillance program during 2013. In order to identify the main pathogenic microorganisms, usually involved in outbreaks of foodborne illnesses (Salmonella enteritidis, Salmonella typhimurium, Campylobacter jejuni/coli, Echerichia coli, Staphylococcus aureus and Listeria moncytogenes, the samples were processed through standardized methods. Based on the obtained results we identified in 214 samples Salmonella enteritidis/typhimurium, 191 samples Escherichia coli 18 samples Staphylococcus aureus. We mention that no Campylobacter and Listeria germs were identified. According to the data gathered from the Infectious disease Hospital, during 201333 foodborne illnesses were confirmed associated with Salmonella enteritidis/typhimurium and 18 with Escherichia coli. Microbial risk in case of Salmonella enteritidis/ typhimurium was increased in the case of poultry meat. Dairy products, respectively cheese manufactured from unpasteurized milk were the most unsafe food of animal origin regarding the risk with $E$. coli. Reducing the incidence of food borne illnesses is a multifactorial process that requires a comprehensive approach to food safety, along the entire food chain, in which farmers, industry, distributors, retailers, consumers, and the competent control authorities must be involved.
\end{abstract}

Keywords: bacterial pathogens, foodborne illnesses; risk assessment

\section{INTRODUCTION}

Global consumer trend is oriented in this century towards a large food processing units coming at the expense of those from conventional production, mainly due to lower costs of processed food industry. However, in recent years it was found that some consumers (mainly those with higher incomes), with access to food information on food quality, began to focus more and more towards traditional foods obtained by 
small producers, many of them in the category of heat-treated foods. It is also growing the food consumption in restaurants, pizzerias and fast food, and during the summer there is an increased consumption of ice cream and cake products based on creams containing milk and eggs. All these products of animal origin may be contaminated with various pathogens, which, after consumption, can cause various food- poisoning in humans. Contamination with pathogens can occur during or after the processing or their marketing. Crosscontamination can occur from improper handling and therefore cross-contamination but most commonly occurs after their unsafe storage and preparation when pathogens are able to survive and multiply, making possible the emergence of true epidemic diseases with serious consequences The interest of the competent authorities regarding foodborne illnesses is increasing these days, although in the last decades it was managed by the combined effort of the food industry and the monitoring system conducted by the state, the decreasing of the prevalence of pathogens in foods of animal origin, and thus the incidence of food poisoning (Quinlan, 2013). Food poisoning were and are some of the most common diseases found in humans, yet often remain undiagnosed, not knowing the true incidence of these. Recent studies show that these food epidemics are in fact 300-350 times more than the reported cases. In the last 20-25 years it was tried the raising of the awareness regarding the public health and the development of surveillance programs (Barbara Lund et al., 2000). This paper aims to assess the risk posed by pathogens (Salmonella enteritidis / typhimurium, Escherichia coli, Listeria monocytogenes, Staphylococcus aureus) in different foods and their occurrence in food poisoning in a regional area during the year 2013. It was also aimed to establish a relationship between the prevalence of different pathogens and food poisoning cases diagnosed in the Infectious Diseases Hospital in the same county, to determine the risk that consumers are exposed too when consuming animal origin products.

\section{MATERIALS AND METHODS}

In order to achieve the objectives, information on the prevalence of pathogens in the period January to December 2013, in foodstuffs of animal origin were processed based on the data provided by the laboratory of the Sanitary-Veterinary and Food Safety Authority, Cluj-Napoca. Information on the incidence of food poisoning that have evolved in the same time period, were processed by using the data provided by the Infectious Diseases Hospital clinics in the studied county. The methods for determining pathogens are standardized in accordance with Regulation (EC) no. 2073/2005 on microbiological criteria for foodstuffs. The samples' processing through classical methods were made in the DSVSA laboratory (Salmonella spp. SR EN ISO 6579/2003 AC/2006, Campylobacter spp. SR EN ISO 10272/2006 and Listeria spp. SR EN ISO 11290/2000/A1/2005, E. coli SR ISO 16649/2007 and Staphylococcus aureus SR EN/ISO 6888-1, 2).

\section{RESULTS AND DISCUSSIONS}

The results regarding the prevalence of Salmonella enteritidis/typhymurium

After processing the results, it was found that for fresh meat, out of 825 samples analyzed, 75 were positive, i.e. $9.09 \%$, issues presented in the graph in Fig. 1.

Regarding the situation of the year 2013, published by the Administration for Inspection and Food Safety (Food Safety and Inspection Service) of the United States, it was shown that of the 17,161 analyzed fresh beef samples, over 170 were positive, representing $1.6 \%$. Samples were randomly taken by the competent authorities during that year and the poor sanitation units were specifically targeted, while in our case, the samples were represented by the ones taken during the strategic programs for the year 2013 and self-control samples done by these units.

In 2013, a total of 400 samples of fresh poultry meat were analyzed. Of these, 110 were positive

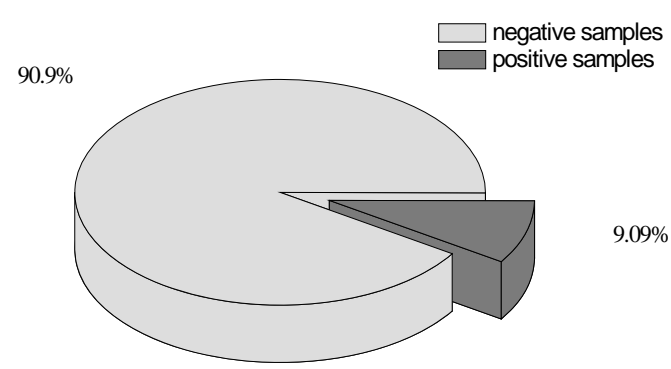

Fig. 1. Prevalence of Salmonella enteritidis/ typhymuriumdin in fresh meat samples during the year 2013 
for pathogenic Salmonella serotypes representing $20.5 \%$, as it can be seen in fig. 2 . These results were lower than the ones reported by the Inspection and Food Safety Administration of the United States of America in poultry samples taken at random which showed $3.9 \%$ positive cases out of a total of 11.124. In the case of processed meat only $0.7 \%$ of the total 2850, were positive for Salmonella enteritidis / typhimurium. Note that of the 20 positive samples, four samples are represented

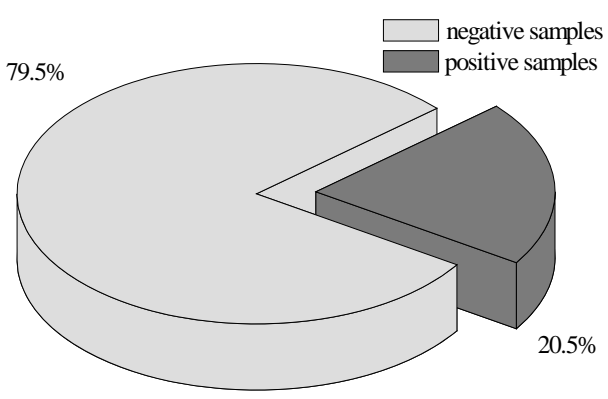

Fig. 2. Prevalence of Salmonella enteritidis/ typhymuriumdin in fresh poultry during the year 2013

by the sausages, which shows that if the heat treatment is insufficient, a situation quite common for these types of products, the risk of Salmonella food poisoning increases. At the analysis of the 46 samples of poultry carcasses, it was found that 9 samples respectively $19.6 \%$ were positive and 37 $(80.4 \%)$ were negative.

Values that were much more lower than the prevalence of Salmonella spp. were mentioned by the Administration and Food Safety Inspection of the USA, where out of 2,955 samples collected, only $2.6 \%$ were positive for Salmonella enteritidis /typhimurium.

This study was conducted also on more than 3,000 ground meat, but none of these samples confirmed the presence of Salmonella enteritidis/ typhimurium. A similar situation was found in the samples of food ready for consumption, in which all samples $(n=1,500)$ were negative.

Following the interpretation of the results in the identification of Salmonella spp., it was found that out of 10,339 samples analyzed during 2013, 2.92\% were positive (214 samples), as shown in Figure 4. In the decreasing order of their Salmonella spp. prevalence, the poultry meat are $1.08 \%$, fresh meat $0.74 \%$, processed meat $0.2 \%$

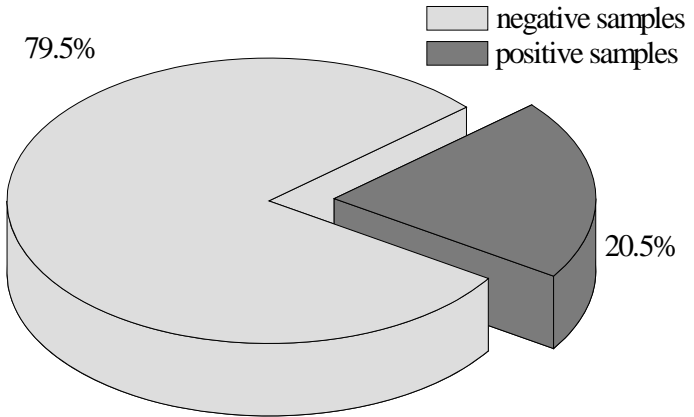

Fig. 3. Prevalence of Salmonella enteritidis/ typhymuriumdin in poultry carcasses during the year 2013

and poultry carcass samples $0.09 \%$. From these results it is shown that the main product with the highest prevalence of pathogenic Salmonella serotypes is the carcass and the deboned poultry meat, issues similar to those mentioned in the literature.

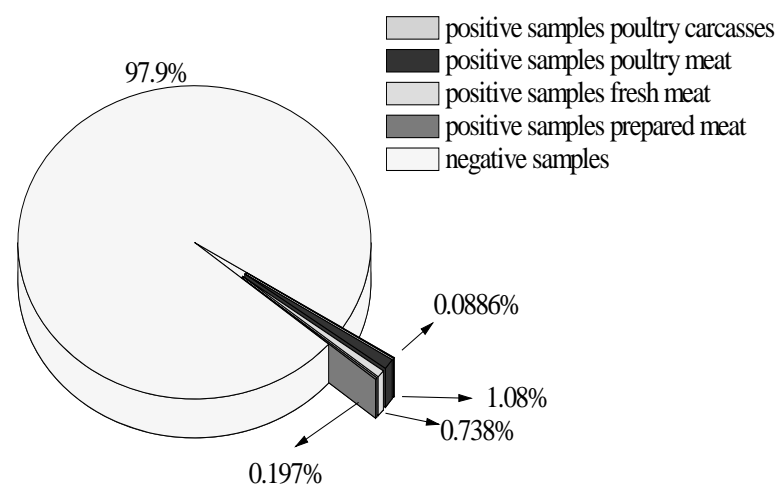

Fig. 4. Prevalence of Salmonella enteritidis/ typhymuriumdin in the meat samples compared to the total amount of samples examined

The results regarding the prevalence of E. coli

During 2013, 59 samples were analyzed in order to identify Escherichia coli in minced meat, of which 10 were positive, representing $16.95 \%$ (fig. 5). Lower levels were reported by Karma (2013), for a period of three years (2006-2008), in a study of 117 samples of minced meat, of which 13 samples were positive $(11.11 \%)$.

In order to identify $E$. coli in foods ready for consumption, 58 samples were subjected to microbiological examination. Of these, 15 were positive, representing $25.86 \%$ of the samples analyzed for E. coli. Lower values have been reported by the Food Safety 
and Inspection Administration of the United States, when 100 samples of ready to eat foods have been tested and $E$. coli was identified in only one sample.

54 samples of pasteurized milk cheeses were tested during 2013 in order to detect $E$. coli, of which 25 were positive, representing 46.3 (Figure 6). Quinto et al. (1996) in a comparative study on 296 samples of cheese made from pasteurized milk (221

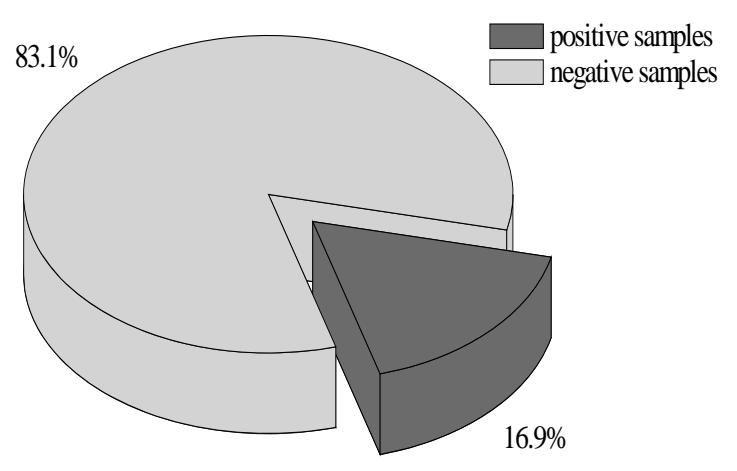

Fig. 5. Prevalence of $E$. coli in the minced meat samples during the year 2013

samples) and from unpasteurized milk (75 samples) reported values much lower for E.coli prevalence. Thus, in pasteurized milk cheeses, E. coli was not identified, and in the samples of unpasteurized milk cheese only 3 samples (1.4\%) tested positive.

130 samples of unpasteurized milk cheeses were collected and analyzed for E. coli prevalence. Of these, 120 were positive (92.3\%) and 10 negative. Similar results were reported in a study made in Brazil in 2003 were 50 samples of cheese tested made from unpasteurized milk, showed the percentage of positive samples of $96.01 \%$.

During the year 2013, 23 samples of liquid dairy products were analyzed in order to identify $E$. coli, of which only two samples were positive $(8.7 \%)$. We did not identify the presence of $E$. coli in the following products: minced chicken meat, processed poultry meat, meat products, mechanically separated meat, fishery products, butter and unpasteurized milk.

Following the interpretation of the results obtained on the presence of $E$. coli in samples of animal products, out of 368 samples, we found a prevalence of $46.73 \%$ (172 positive samples), (fig. 7). The samples positive for E. coli in descending order of their values were taken from: unpasteurized milk cheese (32.61\%), pasteurized milk cheese $(6.79 \%)$, ready-to-eat food $(4.08 \%)$, minced meat $(2.72 \%)$ and the liquid dairy products $(0.54 \%)$. It is noted that the main products identified for E.coli presence are the cheeses made from unpasteurized and pasteurized milk, especially unpasteurized milk.

The results regarding the prevalence of Staphylococcus aureus

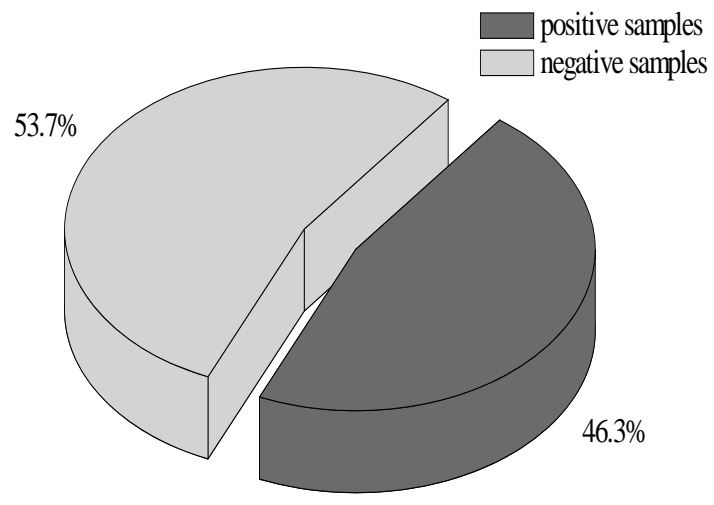

Fig. 6. Prevalence of E. coli in pasteurized milk cheese samples during the year 2013

During 2013, we determined the prevalence of Staphylococcus aureus in 130 samples of animal products. 18 samples $(13.8 \%)$ were positive (Fig. $8)$. In the positive samples, coagulase positive staphylococci load not has exceeded the limits stated by Reg. 1441 (EC)/2007 (<100,000 CFU/g). No testing of samples were required to identify staphylococcal enterotoxin.

Similar results have been reported by Van Loo et al. (2006), in a number of 2217 assays for Staphylococcus aureus, finding that $11.9 \%$ of the samples were positive (264 positive), as follows: beef $(10.6 \%)$, veal $(15.2 \%)$, pork $(10 \%)$, poultry $(16 \%)$, turkey $(35.3 \%)$, mutton $(6,2 \%)$ and rabbit (6.7\%).

For the identification of Listeria monocytogenes 1558 samples were analyzed from the ready to eat food, all samples being negative.

The incidence of food-borne poisonings in the Cluj county during the year 2013

Most samples of animal origin food collected in order to identify pathogens, potential triggers of food poisoning, were from lots that were not subject to veterinary restrictions; as a result, they were delivered to various recipients, where they were purchased by the final consumer. In the case of positive samples for pathogens' presence, until 


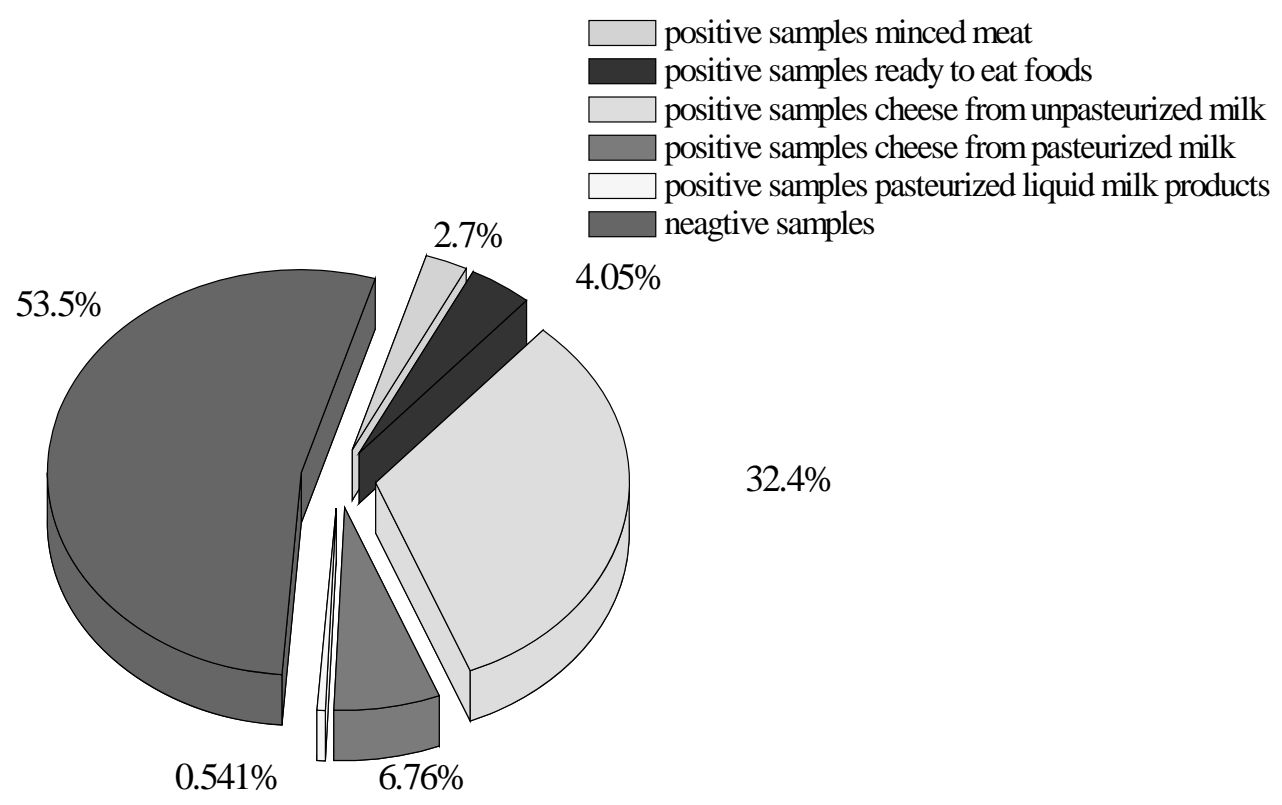

Fig. 7. Prevalence E. coli in food products examined during the year 2013

the identification of the lots and withdrawal from the market, a variable number of packing units of the respective products have been purchased by consumers, which could cause a food poisoning outbreak, when superficial cooking, or contamination of other food products in the kitchen. For products not requiring heat treatment: the case of cheese made from pasteurized or unpasteurized milk, ready to eat food, pasteurized liquid dairy products, food poisoning outbreak risk is higher, especially for people in the category of risk: infants, children, the elderly or those with poor immune system.

From the data collected from the Infectious Diseases Hospital, it was found that over 5,400

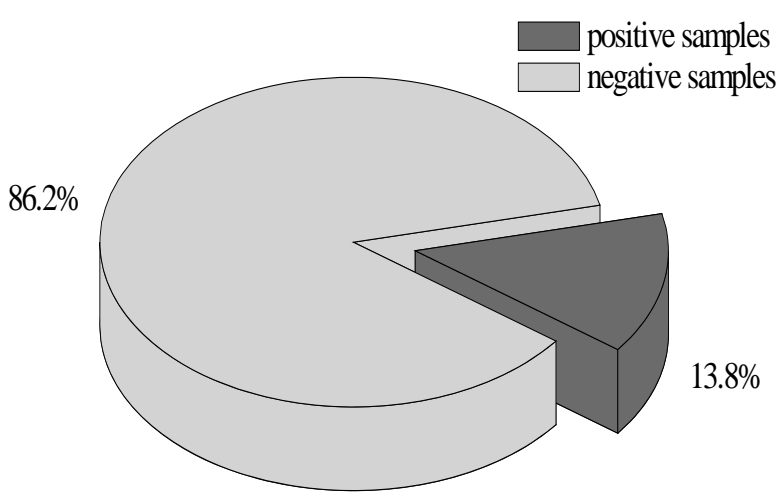

Fig. 8. Prevalence of Staphylococcus aureus in the samples examined during the year 2013 people were investigated with food poisoning-like symptoms: most patients have accused abdominal cramps, dizziness and nausea status, followed by those which were added with vomiting and diarrhea episodes of varying intensity. Based on common epidemiological investigations conducted by joint teams epizootological specialists (physicians and veterinarians), only 45 cases were diagnosed as food poisoning. In these cases, the same pathogen strains were confirmed both in food and the excreta of patients. Thus, in 33 cases the food poisoning with Salmonella was confirmed and the other 12 confirmed the presence of $E$. coli (fig. 8).

Although the incidence of confirmed food poisoning is about $0.9 \%$ lower than in Europe, the actual incidence of these types of diseases might be increased among consumers of animal products. This is due on the one hand particularly to the self-limiting nature of food poisoning. On the other hand, low interest in food provenance and their ignorance to the potential severity of the disease, they prefer not to go the doctor and choose to treat themselves at home, sometimes using medicinal products based on antibiotics purchased from pharmacies without having a prescription. This leads, unfortunately, most of the times to the onset of antibiotic resistance, sometimes with fatal consequences. From talking to some groups of patients, it was found that approximately $10 \%$ of patients choose to come to the infectious diseases clinic for specialist advice, 
the rest choose to treat themselves at home. Of these, about $90 \%$ are healed, considering the selflimiting nature of some food poisoning, but the remaining $10 \%$ come at the hospital with different complications, usually serious.

Another reason that may explain lower food poisoning episodes is represented by the fact that, unfortunately, sometimes in the Infectious Diseases Clinics, the standard protocol for identifying and confirmation of these morbid entities is not respected. The cases are treated as ordinary indigestion or gastro-enteritis without announcing the Department of Public Health which notifies the Sanitary Veterinary and Food Safety Authority, in pursuit of the two institutions specialists to conduct surveys. Comparative analysis of the prevalence of pathogens identified in the animal origin products examined during 2013 (3.67\%), with the food poisoning episodes confirmed to be caused by Salmonella and E. coli $(0.82 \%)$, an acceptable correspondence was found regarding the cause-relationship effect, given the issues mentioned above.

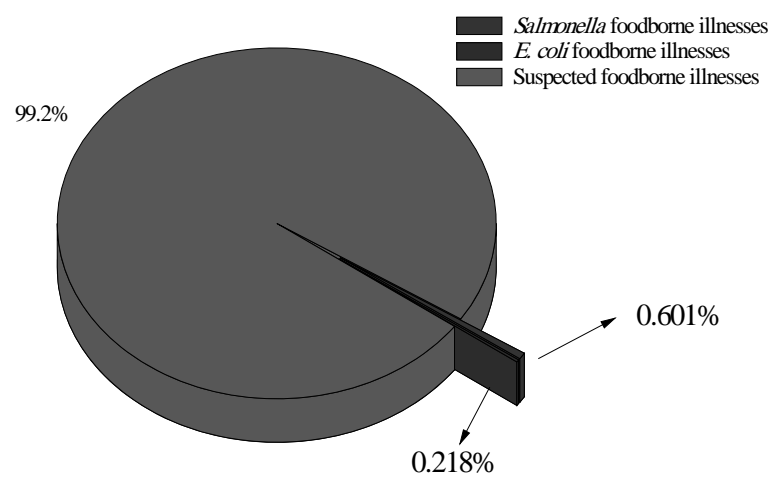

Fig. 9. Incidence of food poisonings with Salmonella and E. coli, during the year 2013, from the total suspected cases

\section{CONCLUSION}

The microbiological risk regarding Salmonella enteritidis / typhimurium presence is significant in the case of poultry meat. Dairy products, namely cheese from unpasteurized milk proved to be the most unsafe food of animal origin regarding the $E$. coli risk, which shows major deficiencies related to the compliance with hygiene, throughout the production process flow of these products. The presence of Staphylococcus aureus, the microbiological risk is high for cheeses made from sheep's milk (curd cheese and fermented), although the load of coagulase-positive staphylococci was below the limit, requiring testing on detection of staphylococcal enterotoxin (below $10^{5} \mathrm{CFU} / \mathrm{g}$ ).

Although the incidence of confirmed food poisoning during the time period under study is low, the actual incidence may be increased, given the multitude of situations that reduce the actual incidence of these morbid entities. The risk related to the possibility of triggering food poisoning is significant, leading to mandatory continuing and thorough analysis of the products that are likely to contain pathogens. The reducing in number of food poisoning episodes is a multifactorial process that requires a comprehensive approach to food safety, the food throughout the supply chain, the need to involve farmers, manufacturers, distributors, retailers and consumers, and the competent control authorities.

\section{REFERENCES}

1. de Boer E, Zwartkruis-Nahuis JTM, Wit B, Huijsdens XW, de Neeling AJ, Boschc T, van Oosteromb RAA, Vila A, Heuvelink AE (2009). Prevalence of methicilin-resistant Staphylococcus aureus in meat, International Journal of Food Microbiology, International Journal of Food Microbiology 134:52-56.

2. Lund B, Baird-Parker AC, Gould GW. (2000). Microbiological Safety and Quality of Food, Springer.

3. Quinlan J (2013). Foodborne Illness Incidence Rates and Food Safety Risks for Populations of Low Socioeconomic Status and Minority Race/Ethnicity: A Review of the Literature. Int. J. Environ. Res. Public Health 2013, 10, 3634-3652; DOI:10.3390/ijerph10083634.

4. van Loo IHM, Diederen BMW, Savelkoul PHM, Woudenberg JHC, Roosendaal R, van Belkum A, Lemmens-den Toom N, Verhulst C, van Keulen PHJ JAW. (2006). MethicilinResistant Staphylococcus aureus in Meat Products, Emerg Infect Dis. Nov 2007; 13(11): 1753-1755.

5. *** Regulamentul (CE) nr. 1441/2007 al Comisiei din 5 decembrie 2007 de modificare a Regulamentului (CE) nr. 2073/2005 privind criteriile microbiologice pentru produsele alimentare.

6. *** SR EN ISO 6579/2003, SR EN ISO 6579 AC/2009, Metoda orizontală pentru detectarea bacteriilor din genul Salmonella.

7. *** SR EN ISO $11290-1 / 2000$, SR EN ISO 11290-1/A1 2005, Metoda orizontală pentru detectarea şi numărarea Listeria monocytogenes.

8. *** SR EN ISO 16649-2/2007, Metoda orizontală pentru numărarea Escherichia coli pozitivă la $\beta$-glucuronidază.

9. *** WHO, 1995. Surveillance Programme. Sixth Report of WHO surveillance Programme for control of some food Infections and intoxications in Europe Berlin: FAO/WHO collaborating centre for Research and Training in food Hygiene and zoonosis. 